\title{
HIGH SCHOOL STUDENTS' PERCEPTIONS OF CYBERSECURITY: AN EXPLANATORY CASE STUDY
}

\author{
Kodey S. Crandall, Dakota State University, kodey.crandall@trojans.dsu.edu \\ Cherie Noteboom, Dakota State University, cherie.noteboom@dsu.edu \\ OmarEl-Gayar, Dakota State University, omar.el-gayar@dsu.edu \\ Kalee Crandall, Utah State Board of Education, kalee.crandall@schools.utah.gov
}

\begin{abstract}
The need for additional cybersecurity experts is greater than ever before. Research has been conducted on how to increase the number of security specialists, improve cybersecurity curriculum, identify the needed skills of a cybersecurity professional, and overcome negative perceptions in organizations. It appears, however, there is limited research regarding perceptions of high school students that may prevent them from exploring this occupation. While there are undoubtedly many reasons students choose to pursue other occupations, this study examined 237 high school students at one of the highest performing secondary schools in the Mountain State Region of the United States in attempt to explain what perceptions influence a high school student's choice to pursue a career in cybersecurity. The qualitative coding process produced seven unique categories. These key categories provide insight into the careermaking processes of secondary students regarding cybersecurity. Our findings also reveal significant gender differences in perceptions of the field.
\end{abstract}

Keywords: Cybersecurity, Career decision-making, Workforce, Theory of Vocational Development, Self-efficacy

\section{INTRODUCTION}

The protection of U.S. computer systems requires an increase in information security experts. As of August 2017, there were an estimated 299,000 active openings for cybersecurity-related jobs in the United States. However, by the year 2020 projections suggest a cybersecurity workforce shortage of 1.8 million by 2022 (The Secretary of Commerce \& The Secretary of Homeland Security, 2017). In a 2017 report to the President, the Secretary of Commerce, Wilbur Ross, and Secretary of Homeland Security, Elaine Duke, presented findings and recommendations regarding how to support the growth and sustainment of the Nation's cybersecurity workforce in both the public and private sectors. One suggestion included integrating cybersecurity concepts into our primary and secondary education curricula to generate early interest in cybersecurity.

"The federal government must lead in the effort to close U.S. cybersecurity workforce gaps-something that can be achieved only by changing the way the country views and practices cybersecurity" (p.5).

Research on the perceptions of high school students of cybersecurity is in its infancy. This explanatory, single-case study will focus on exploring perceptions to answer the research question: What perceptions influence a high school student's choice to pursue a career in cybersecurity? We first focus on the literature and theories that influence the career decision-making processes of adolescents, specifically $9^{\text {th }}-12^{\text {th }}$ grade high school students. The next sections of this paper focus on the research methodology, analysis, and findings. We conclude by discussing the results and providing recommendations for research and practice.

\section{LITERATURE REVIEW}

Research has focused on the career decision-making process of high school students (Avsec \& Jamšek, 2018; Blackhurst, Auger, \& Wahl, 2003; Buschor, Kappler, Frei, \& Berweger, 2014; Edwin \& Prescod, 2018; Galliott \& Graham, 2015; Gaylor \& Nicol, 2016; Hijazi, Tatar, \& Gati, 2004; Kim, 2011; Mau \& Bikos, 2000; Theresa, 2015). The choices made during these formative years can shape the course of an individual's entire life (Albert Bandura, 


\section{Issues in Information Systems}

Volume 20, Issue 3, pp. 74-82, 2019

1997). These young students also begin to develop an awareness of occupations and recognize the need to make career decisions (Super, 1957). Also during this period students become aware of their interests and abilities and how they are related to work opportunities (Super, 1957) and focus on internal characteristics such as motivation, values, and ability to guide them in the career decision-making process (Gottfredson, 1981). Between the ages of 15 and 24, individuals develop an awareness that helps them begin to identify possible fields and levels of work consistent with perceived abilities and interests (Super, 1957).

Motivation and ability are impacted by perceived self-efficacy. Perceived self-efficacy refers to an individuals' beliefs about their capabilities to produce effects (Bandura, 1997). Unless people believe they can produce desired outcomes by their actions, they have little incentive to act, or in this case, consider a certain career path. People simply disregard occupations they believe to be beyond their capabilities, however attractive the occupations may be, which is why perceived self-efficacy is a crucial factor in career choice and development (A. Bandura, Barbaranelli, Caprara, \& Pastorelli, 2001).

Despite active efforts to raise awareness in cybersecurity, the field continues to experience a shortage of individuals interested in the career, which is a significant concern for educators, policymakers, and researchers. To meet the federal government's goal to close the U.S. cybersecurity workforce gaps, more needs to be done to understand high school students' perceptions of cybersecurity and what barriers influence their career choice formulation. Barriers represent negative outcome expectations related to a career (Swanson, Daniels, \& Tokar, 1996) and can be conceived and operationalized as a particular form of outcome expectation related to one's perception of the environment (Lent, Brown, \& Hackett, 2000).

In the Internet Age, there is an abundance of information about different occupations. Students who are given opportunities to explore a variety of occupations may be more likely to have an accurate knowledge of career expectations and requirements. However, if resources are unknown, inaccurate, or unavailable to students, faulty perceptions may also occur. Super (1957) believes that if knowledge of any occupation is inaccurate, that occupation is not going to be well evaluated concerning one's self-concept. Holland's theory of vocational choice (1997) maintains the importance of accurate occupational knowledge and suggests that for an occupational choice to be appropriate, the individual must have accurate occupational knowledge, accurate self-knowledge, and accurate selfevaluation. According to Holland's theory, if a person and an environment are the same or similar, then the person will likely be satisfied and persist in that environment. This satisfaction will result from individuals being able to express their personalities in supportive environments that include other persons who have the same or similar personality traits (Holland, 1997).

Not only does having accurate occupational knowledge increase the likelihood of job satisfaction, but research (Mau \& Heim Bikos, 2000) has also shown that when students have an accurate understanding of the education or other vocational training required for specific occupations, they will have higher occupational aspirations and aspire to greater educational attainment. However, if a student fails to develop this accurate knowledge, just the opposite may occur. Having accurate knowledge of an occupation, including educational and vocational training requirements, is essential to the development of realistic, and congruent, educational and occupational aspirations (Theresa, 2015) and can influence perceptions that may prevent students from studying a certain occupation.

The focus on this research is to explore perceptions of high school students regarding cybersecurity in attempt to understand what is preventing them from considering a career in this field. Perception is an individual's construction of his or her reality. For this reason, there is potential for perceptions to be affected by an individual's self-concept. Self-concept is the total of all the beliefs people hold about themselves, including personality, interests, and perceived place in society (Gottfredson, 1981). According to Gottfredson's (1981) Theory of Circumscription of Compromise, occupational aspirations are a reflection of one's self-concept. People seek occupations that (a) are congruent with their self-image and (b) reflect their knowledge of different occupations (Figure 1). High school students' perceptions of a career leads them to draw conclusions on which line of work they are best suited for and often causes them to rule out possible careers in which they are only dimly aware (Gottfredson, 2002). 


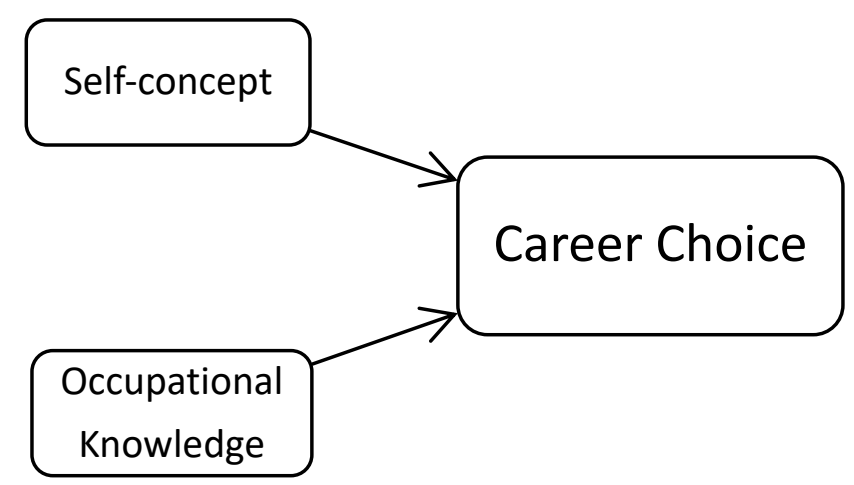

Figure 1. Factors leading to career choice

\section{RESEARCH APPROACH AND METHODOLOGY}

The study used a qualitative research method to investigate high school perceptions of the cybersecurity field as a career option. The guiding research question was: What perceptions influence a high school student's choice to pursue a career in cybersecurity? The chosen research design was a single explanatory case-study, as (Yin, 2018) tells us a case study method is appropriate when investigating a phenomenon in depth and within its real-world context and when the boundaries between phenomenon and context may not be clearly evident. To investigate high school students' perceptions of the cybersecurity field, the research employed Eisenhardt's (1989) case study approach by using surveys as the primary data collection, observation, and document gathering as secondary methods of data collection.

Open coding was used to analyze the data and develop concepts as they relate to high school student perceptions related to cybersecurity field. The qualitative method and open coding analysis enabled discovery of relationships in the real-world situation. Theoretical sensitivity allowed the researchers to obtain insight and give meaning to the events and happenings in the data. "Insights do not occur haphazardly; rather, they happen to prepared minds during interplay the data" (Strauss \& Corbin, 1998, p. 47).

This combination of research methods enabled concepts and relationships to be arrived at and then assessed using the enfolding literature from Eisenhardt and theoretical sensitivity from open coding.

\section{DATA COLLECTION}

\section{Study Participants}

The target population for this study was high school students at one of the largest, most affluent secondary public schools in the Mountain Region in the United States. Two hundred and thirty-seven participants provided qualitative responses to one open-ended question. The data were collected between February and March, 2019. The survey was administered in a computer lab during regular school hours with assistance from school counselors and students were given 15 minutes to complete the survey.

The sample population consisted of $8210^{\text {th }}$ grade students $(34 \%), 7611^{\text {th }}$ grade students $(32 \%)$, and $7912^{\text {th }}$ grade students (34\%) as shown in Table 1. There were 110 male students (46\%), and 128 female students (54\%) surveyed. Almost $98 \%$ of the population sampled stated they had a GPA above 3.1 (Table 2). 
Table 1. Population by Gender \& Grade Level

\begin{tabular}{|l|l|l|}
\hline Female & Female & Male \\
\hline 10th Grade & 41 & 41 \\
\hline 11th Grade & 41 & 35 \\
\hline 12th Grade & 46 & 33 \\
\hline
\end{tabular}

Table 2. Student GPA

\begin{tabular}{|c|c|}
\hline \multicolumn{2}{|c|}{$\begin{array}{l}\text { What is your approximate Grade Point } \\
\text { Average (GPA)? }\end{array}$} \\
\hline 4.0 to 3.1 ; Grades $\mathrm{A}$ to $\mathrm{B}$ & 206 \\
\hline 3.0 to 2.1 ; Grades $\mathrm{B}$ to $\mathrm{C}$ & 26 \\
\hline 2.0 to 1.1 ; Grades $\mathrm{C}$ to $\mathrm{D}$ & 4 \\
\hline GPA not provided & 1 \\
\hline Grand Total & 237 \\
\hline
\end{tabular}

\section{Instrumentation}

The research question, "What perceptions influence a high school student's choice to pursue a career in cybersecurity?" was explored using one open-ended item: "What would prevent you from exploring training or a career in cybersecurity?" The investigators developed this survey question based on a review of the literature and recommendations from educational experts in cybersecurity. A survey design provides a quantitative description of some fraction of the population, that is, the sample through the data collection process of asking questions (Fraenkel \& Wallen, 1995). This method was applied in the collection of data from the field to provide insight into the careermaking processes of secondary students regarding cybersecurity. The descriptive survey was chosen for the study for the fact that it determines the status of a given phenomenon as contended by (Osuala, 2001).

\section{Data Analysis}

While analyzing the responses, "labels of meaning" were identified and placed next to the relevant occurrence. Occurrences were events, happenings, actions, feelings, perspectives, actions, and interactions. Categorization of the coding was done in two phases. First, the data obtained from the survey was analyzed using Straus \& Corbin's (1998) open coding method. Open coding was used to conceptualize raw data by naming and categorizing the phenomena through close examination of the data. During open coding, the data was broken down into discrete parts, closely examined and compared for similarities and differences. The coding process yielded 471 coded quotes. The data representing events, happenings, actions, and interactions that were found to be conceptually similar in nature or related in meaning were grouped under abstract concepts that best represent the phenomenon. According to Strauss and Corbin (1998), although events or happenings might be discrete elements, the fact that they share common characteristics or related meanings enable them to be grouped. Based on their ability to explain what is going on, certain concepts were grouped under more abstract higher-order concepts which Straus and Corbin (1998) call category. Categories have analytic power because they can have the potential to explain why high school students' perceptions are influenced to consider or to refrain from cybersecurity field opportunities. The 471 labels were categorized to compare codes across the survey responses. The categories were derived by tabulating the number of occurrences of related concepts.

Reliability of these groupings was achieved through theoretical sensitivity, iterative coding, and theoretical sampling. Straus and Corbin (1998) suggest that theoretical sensitivity is required to enable the researchers to interpret and define data and thus develop relationships, models or theories that are grounded, conceptually dense and well-integrated. Sources of theoretical sensitivity are the literature, professional and personal experiences. Additional reliability was achieved through the iterative use of open and axial coding to bring out the concepts and discover any causal relationships or patterns in the data. Strauss \& Corbin (1998, p. 98) state that "though open and axial coding are distinct procedures, when the researcher is actively engaged in the analysis, he or she alternates between the two modes." Along with the grouping of abstract concepts (open coding) and identification of causal conditions (axial coding), additional coding was completed iteratively using theoretical sampling. Glaser and Straus (1967, p.3) state that the researcher does not approach reality as tabula rasa but must have a perspective that will help him or her abstract significant categories from the data based on the constructs identified in the literature. Two independent coders completed the coding analysis.

Nine categories emerged from student responses. The kappa coefficients were evaluated using the guidelines outlined by Landis and Koch (1977) where the strength of the kappa coefficients are as follows: slight $=0.01-0.20$; fair $=0.21$ $0.40 ;$ moderate $=0.41-0.60 ;$ substantial $=0.61-0.80 ;$ almost perfect $=0.81-1.00($ Landis $\&$ Koch, 1977). Of the nine 
categories, two had moderate agreement, six had substantial agreement, and one had almost perfect agreement. The Cohen's Kappa for each category is shown in Table 3.

\section{RESULTS}

The data analysis produced the following categories derived from the open coding process: lack of occupational interest, lack of occupational awareness, lack of occupational aspirations, occupational interest, lack of excitement, lack of self-efficacy, lack of resources, and unspecified as shown in Table 3.

Table 3. Categories and Cohen's Kappa

\begin{tabular}{|l|r|r|}
\hline Category & Count & Kappa \\
\hline Lack of Occupational Interest & 108 & .7513 \\
\hline Lack of Occupational Awareness & 82 & .7944 \\
\hline Lack of Occupational Aspirations & 76 & .4881 \\
\hline Occupational Interest & 74 & .7377 \\
\hline Lack of Excitement & 49 & .7366 \\
\hline Lack of Self-efficacy & 46 & .5678 \\
\hline Lack of Resources & 27 & .7686 \\
\hline unspecified & 26 & .7135 \\
\hline (blank) & 10 & 1 \\
\hline
\end{tabular}

Lack of Occupational Interest. The category, lack of occupational interest, relates to a student's perception that the career is not of interest to them based on their self-concept (Gottfredson, 1981). There were 108 coded instances (22\%) that showed students without an interest in the field of cybersecurity. This lack of occupational interest may stem from other categories identified in this research such as a lack of self-efficacy or lack of excitement.

Responses: "Not interested", "I feel like it would not be interesting", "It doesn't interest me", "It doesn't sound appealing"

This category may also represent students' perceptions or preferences for other types of work. Instances below indicate these students have given thought to the occupational choices available to them and are aware of their interests and abilities and how they are related to work opportunities (Super, 1957). This finding may validate the role of the school counselor in the career decision-making process.

Responses: "I cannot sit at a computer all day", "I want face-to-face work helping others", "It just doesn't jive with me”

Lack of Occupational Awareness. According to Super (1957), a lack of occupational awareness occurs when adolescents are not aware of their interests and abilities and how they are related to work opportunities. To determine if students had accurate occupational awareness, responses that included any perception of required skills or work context were analyzed and compared to occupational information found in the report to the United States President (The Secretary of Commerce \& The Secretary of Homeland Security, 2017) and O*Net. O*Net is an online database developed under the US Department of Labor/Employment and Training Administration that contains occupational information about hundreds of occupations. Results showed that there were 82 coded instances (16\%) of responses showing students had little understanding about this career field, didn't know what would prevent them from entering this field, or had an inaccurate perception of work context.

Responses: "Not paying well enough", "I don't know much about it", "What is cyber security?", "I don't know anything about it", "Unsure what a career would be" 
Lack of Occupational Aspirations. Gottfredson (1981) states aspirations are a reflection of one's self-concept. People seek occupations that are congruent with their self-image and reflect their knowledge of different occupations. There were 76 coded items (15\%) that mentioned key components of the occupation that were not congruent with a student's self-image.

Responses: "I'm not very interested in technological studies, or coding, and all that", "I don't like that stuff", "I really hate computer and most technology", "I don't like cybersecurity"

Occupational Interest. There were 74 (15\%) of coded instances where students showed interest in pursuing training or a career in cybersecurity.

Responses: “...I'm interested”, "Pretty sick actually”, “...I'm quite intrigued by the career"

Lack of Excitement. There were 49 coded instances (10\%) that described a career in cybersecurity to be dull, or as many students stated that it is a boring field. Furthermore, females were more than twice as likely to have this perception than males. This may contribute to women being underrepresented among those working in cybersecurity (The Secretary of Commerce \& The Secretary of Homeland Security, 2017).

Responses: "I have a hard time not immediately labeling it as boring", "There's no way that it's not boring 99\% of the time", "Sounds boring"

Lack of Self-Efficacy. The category, lack of self-efficacy, is based on the perception that the student wouldn't be successful in the career (Super, 1957), or in other words, the occupation requires skills beyond his or her capabilities (A. Bandura et al., 2001). There were 46 coded instances (9\%) that fit into this category and included responses where students indicated a lack of skills needed to be successful in the field, a lack of motivation to learn the material, and not having the ability to succeed due to poor grades.

Responses: "It sounds hard", "Lack of motivation", "Lack of skills in coding”, "I'm not good with tech"

Lack of Resources. There were 27 coded instances $(5 \%)$ that were related to a lack of resources. Students in this category were those who did not have the perceived ability to pursue training or a career in cybersecurity due to cost, time, and family responsibilities.

Responses: "My financial situation", "Time-consuming", "Cost", "Money”

Unspecified/Blank. There were 36 (7\%), coded instances where there was either not enough information to determine the code, the information was irrelevant to the question, or there was no response. Ten of these instances resulted from students not answering the question.

\section{DISCUSSION \& RECOMMENDATIONS}

The categories that were discovered from this case study can assist researchers and educators in understanding the unique perceptions students have about cybersecurity. Based on these findings, we recommend increasing high school students' occupational knowledge of cybersecurity and helping them identify and develop the necessary skills, abilities, and self-efficacy needed to be successful in the field. To increase student's self-efficacy, we recommend following the suggestions from Bandura (1997) by 1) providing opportunities for mastery experiences, 2) providing social models, and 3) increasing self-efficacy through social persuasion.

Perhaps the most effective way to increase awareness, the number of cybersecurity professionals, and job satisfaction, is to introduce students to opportunities to participate in cybersecurity activities which can give them job-related experiences. Students" perceptions of cybersecurity being "dull" or "boring" may stem from a misunderstanding of how cybersecurity can affect them. Cybersecurity advocates attempt to overcome this perception and provide mastery 


\section{Issues in Information Systems}

Volume 20, Issue 3, pp. 70-78, 2019

experiences by engaging students using virtual scavenger hunts, hack-a-thon challenges, and security camps. Activities such as these not only generate interest but can also help students gain a better understanding of the field.

Social models are critical to increasing the number of cybersecurity professionals, especially among women. According to the individual differences theory factors that influence a woman's decision to enter and remain in the IT field are a combination of personal characteristics possessed by the individual and influences experienced by that individual, including role models and mentors (Trauth, Quesenberry, \& Morgan, 2004).

Social persuasion involves more than just providing encouragement. To accurately persuade an adolescent that they have the ability to succeed, a cybersecurity advocate must avoid placing them in situations prematurely where they are likely to fail. Further research is needed to determine what high students understand about the field of cybersecurity, including the training requirements and work context. Future research should also focus on the gender gap of high school students in the career decision-making process. This research focused on what perceptions influence a high school student's choice to pursue a career in cybersecurity; however, additional research is needed to discover why student's hold these perceptions.

Future research should also focus on the difference in male and female perceptions of cybersecurity. Our analysis revealed significant gender gaps in the perceptions between these two groups; particularly in their lack of occupational interest, lack of excitement, and lack of resources as shown in Table 4. However, while there are many differences between their perceptions, the data revealed females had the same perceived self-efficacy as males. It appears both genders feel they are equally qualified to pursue a career in cybersecurity.

Table 4. Categories by Gender

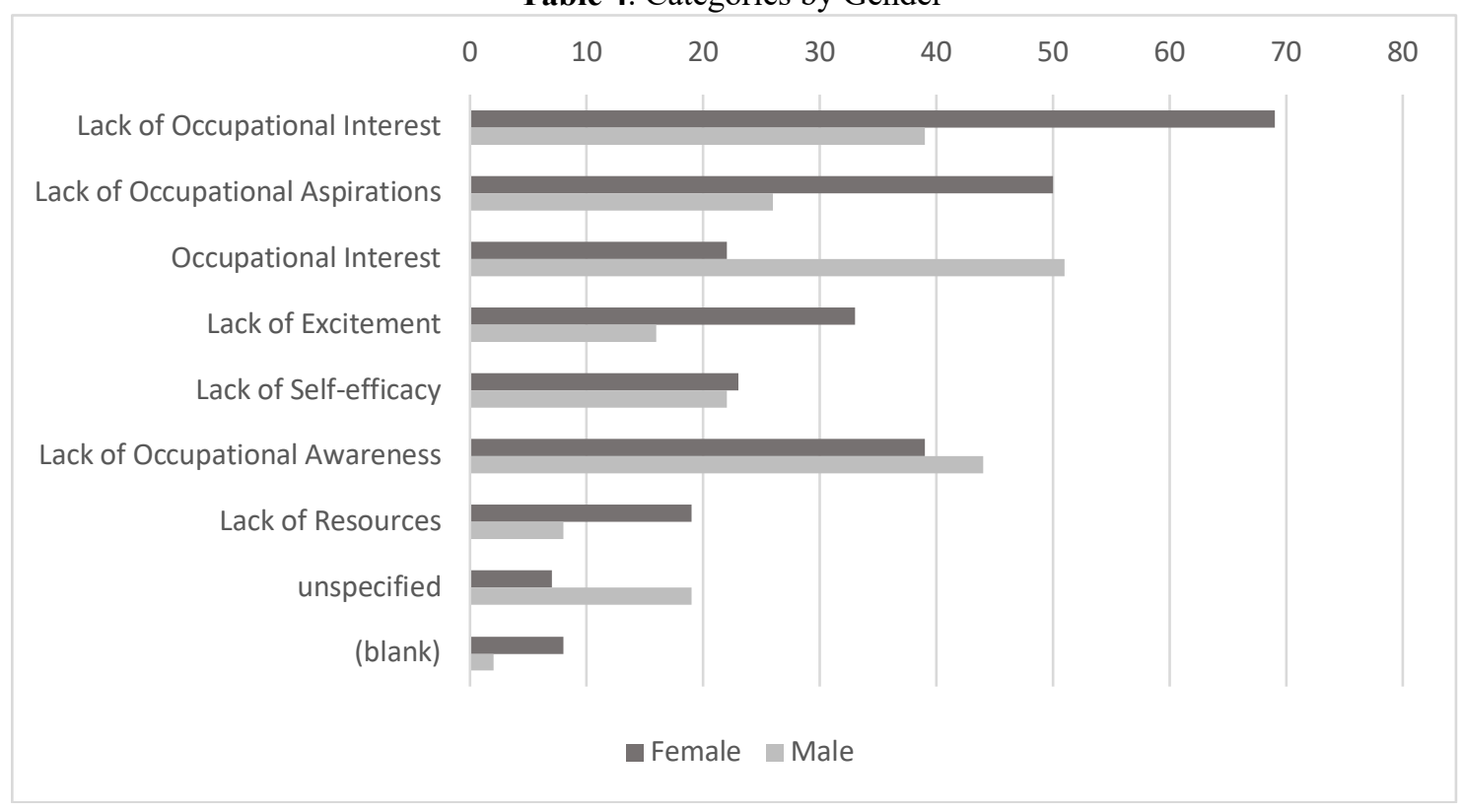

\section{CONCLUSION}

The findings of this study suggest there are various perceptions students hold of cybersecurity that may hinder them from considering this as a future career. The majority of respondents reported a lack of occupational interest in the field, possibly due to faulty perceptions of the work context or a perceived lack of self-efficacy. Other respondents reported resource barriers such as cost, motivation, and time associated with training. Ultimately, to increase the number of professionals in the field, there must be early interventions aimed at providing mastery experiences, social models and social persuasion to ensure accurate knowledge of the profession. Providing accurate occupational knowledge to students at an early age, in addition to helping them develop accurate self-knowledge and self-efficacy, will enable them to make appropriate occupational choices, including a possible career in cybersecurity. 


\section{Issues in Information Systems}

Volume 20, Issue 3, pp. 70-78, 2019

This research is limited as it is a single case study representing the student body at a high performing secondary school in the Mountain Region. Future research should ensure more diversity in the student population so the findings can be more generalizable to other schools, particularly schools that may have different demographics. Limitations to this research include the method of data collection. The results came from an online survey questionnaire where most students only replied without opportunity for verification. By using follow-up interviews, researchers could gain richer insight into the categories identified in this study. This research is our first step towards building future research to understand the perceptions influencing a high school student's choice to pursue a career in cybersecurity.

\section{REFERENCES}

Avsec, S., \& Jamšek, J. (2018). A path model of factors affecting secondary school students’ technological literacy. International Journal of Technology and Design Education, 28(1), 145-168. doi:10.1007/s10798-0169382-z

Bandura, A. (1997). Self-Efficacy: The Exercise of Control (Vol. 1): Worth Publishers.

Bandura, A., Barbaranelli, C., Caprara, G. V., \& Pastorelli, C. (2001). Self-efficacy beliefs as shapers of children's aspirations and career trajectories. Child development, 72(1), 187.

Blackhurst, A. E., Auger, R. W., \& Wahl, K. H. (2003). Children's Perceptions of Vocational Preparation Requirements. Professional School Counseling, 7(2), 58-67.

Buschor, C., Kappler, C., Frei, A., \& Berweger, S. (2014). I want to be a scientist/a teacher: students' perceptions of career decision-making in gender-typed, non-traditional areas of work. Gender and Education, 26(7), 743. doi:10.1080/09540253.2014.970615

Edwin, M., \& Prescod, D. (2018). Fostering Elementary Career Exploration with an Interactive, Technology-Based Career Development Unit. Journal of School Counseling, 16(13), 29.

Eisenhardt, K. M. (1989). Building theories from case study research. Academy of Management Review, 14(4), 532550.

Fraenkel, J. R., \& Wallen, N. E. (1995). How to Design and Evaluate Research in Education. Englewood Cliffs: Prentice Hall.

Galliott, N. y., \& Graham, L. (2015). School based experiences as contributors to career decision-making: findings from a cross-sectional survey of high-school students. Aust. Educ. Res., 42(2), 179-199. doi:10.1007/s13384-015-0175-2

Gaylor, L., \& Nicol, J. (2016). Experiential High School Career Education, Self-Efficacy, and Motivation. Canadian Journal of Education, 39(2), 1-24.

Gottfredson, L. S. (1981). Circumscription and compromise: A developmental theory of occupational aspirations. Journal of Counseling Psycology, 28, 545-579.

Gottfredson, L. S. (2002). Gottfredson's Theory of Circumscription, Compromise, and Self-Creation. San Francisco, CA: Jossey-Bass.

Hijazi, Y., Tatar, M., \& Gati, I. (2004). Career Decision-Making Difficulties Among Israeli and Palestinian Arab High-School Seniors. Professional School Counseling, 8(1), 64-72. 
Holland, J. L. (1997). Making vocational choices: A theory of vocational personalities and work environments (Vol. 3). Odessa FL.

Kim, M. (2011). The Relationship Between Thinking Style Differences and Career Choices for High-Achieving Students. Roeper Review, 33(4), 252-262. doi:10.1080/02783193.2011.603113

Landis, J. R., \& Koch, G. G. (1977). The measurement of observer agreement for categorical data. Biometrics, 33, $159-174$.

Lent, R. W., Brown, S. D., \& Hackett, G. (2000). Contextual Supports and Barriers to Career Choice: A Social Cognitive Analysis. Journal of Counseling Psychology, 47(1), 36.

Mau, W.-C., \& Bikos, L. H. (2000). Educational and Vocational Aspirations of Minority and Female Students: A Longitudinal Study. Journal of Counseling \& Development, 78(2), 186-194. doi:10.1002/j.15566676.2000.tb02577.x

Osuala, E. C. (2001). Introduction to Research Methodology. Ibadan: Africana-Fep Publishers Ltd.

Strauss, A., \& Corbin, J. M. (1998). Basics of qualitative research: Grounded theory procedures and techniques (2nd ed.). Thousand Oaks: US: Sage Publications, Inc.

Super, D. (1957). The Psychology of Careers. New York: Harper \& Row.

Swanson, J. L., Daniels, K. K., \& Tokar, D. M. (1996). Assessing perceptions of career-related barriers: The Career Barriers Inventory. Journal of Career Assessment, 4, 219-244.

The Secretary of Commerce \& The Secretary of Homeland Security. (2017). Supporting the Growth and Sustainment of the Nation's Cybersecurity Workforce: Building the Foundation for a More Secure American Future Retrieved from https://www.dhs.gov/sites/default/files/publications/eo_wf_report_to_potus.pd_pdf

Theresa, L. D. (2015). Factors that Inform Students' Choice of Study and Career. Journal of Education and Practice, 6(27), 43-49.

Trauth, E., Quesenberry, J., \& Morgan, A. (2004). Understanding the under representation of women in IT: toward a theory of individual differences. In (pp. 114-119).

Yin, R. K. (2018). Case Study Research and Applications (Vol. 6). Thousand Oaks, CA: SAGE. 